\title{
Spatial Spillover Effects of Public Services on Factor Income--Based on Changes in Variable Costs
}

\author{
Jing $\mathrm{Li}^{1,2, *}$ and Qingnian Zhang ${ }^{2}$ \\ ${ }^{I}$ School of Transportation, Wuhan University of Technology, Wuhan, Hubei, 430063, China \\ ${ }^{2}$ School of Economics and Management, Hulunbuir University, Hulun Buir, Inner Mongolia, 021008, China
}

\begin{abstract}
In this paper, from the perspective of spatial economics, we studied the spatial spillover of public services and their effect on factor income. We establish a Nonlinear General Equilibrium Model, which contains "two regions, two sectors and two elements". For the determination of the spill-over effect, using Matlab mathematical software to draw a furger, through the mathematical method of derivative, we discuss the impact of public service on the factors' such as flow and spatial distribution. The study found that public services can increase the rate of factor income and facilitate the flow of factors of production.
\end{abstract}

Keywords: Factors, Public services, Spillover effect.

\section{INTRODUCTION}

With the accelerated process of economic globalization, inter-regional linkages have become ever more closely, exchanges become more frequent, spillover effects of public services are increasing day by day. The local public service overflow, especially the accurate public service overflow, makes the income boundaries become blurred. With the increasing public goods, the cost of living and manufacture is reduced, the private sector reaps more revenue, and agglomerating and radiating effects are promoted. From the perspective of spatial economy, this paper studied the effect of spatial spillover effects on factor income of the public service [1,2].

\section{MODEL}

The economy considered in this paper is made up of two regions, which is composed of the private sector and the public sector. Factors used by the public sector do not have the space of liquidity, shown by the characteristics of constant returns to scale. Factors used by the private sector are mobile and shown by the characteristics of increasing returns to scale. The private sector is produced in the monopolistic competition under the framework of D-S. At the early stage, two areas are symmetrical in all aspects [4-7].

\subsection{Production Costs of the Private Sector}

Assuming that the unit cost of the private sector is $F+a_{m} X$, where $F$ indicates fixed cost (immobile) and $a_{m} X_{i}$ indicates variable factor cost (mobile). The public services have spatial spillover effect, so that variable costs of the private products are reduced. The degree of reduction is

*Address correspondence to this author at the School of Transportation, Wuhan University of Technology, Wuhan, Hubei, 430063, China; E-mail: lijingying23@163.com proportionate to the amount of overflow of the public service. The unit cost can be expressed as follow:

$$
F+a_{m} \frac{1}{k} x
$$

where $k \geq 1$ indicates spatial spillover effects of the public services. The cost function of region $\mathrm{A}$, that is affected by the spatial spillover effects from region $\mathrm{B}$, is as follows:

$$
W_{A}\left(F+a_{m} \frac{1}{k_{B}} x\right)
$$

Where $W_{A}$ denotes factor prices and $k_{B} \geq 1$ denotes spatial spillover effects of the public service in region $B$ [8$10]$.

Similarly, the cost function of region B is as follows:

$$
W_{B}\left(F+\frac{1}{k_{A}} a_{m} X\right)
$$

\subsection{The Price of Private Goods}

Under the Dixit - Stiglitz construct, the article discussed the private sectors. They are monopoly enterprises, facing a completely competitive market and a demand curve with constant elasticity. The assumption is that there is no economies of scale or diversification, and enterprises are independent [11]. Each product has the same fixed cost and the same marginal cost. This means that an enterprise will produce a product, i.e. the number of enterprises is equal to the types of products and the prices of products in an economic system are the same. According to the principle of profit maximization,

$$
\max \left\{\boldsymbol{\pi}=p X-W\left(F+\frac{1}{k} a_{m} X\right)\right\} \text { s.t } x_{i}=1 p^{-\sigma}
$$


Among above, $P$ denotes product price and $\sigma$ denotes elasticity. By solving the optimization problem, we get private product price of region $\mathrm{A}$ :

$p_{A}=\frac{1}{k_{B}} w_{A} a_{m} /(1-1 / \sigma)$

Similarly, private product price of B region is as follows:

$p_{B}=\frac{1}{k_{A}} w_{B} a_{m} /(1-1 / \sigma)$

Assume that the goods sold in the local have zero transportation cost, transportation costs to another area is $\tau(\tau<1)$, and the price on local markets is $P$. The firm is a price setter in the local markets, so it sets a price equal to the delivered price at other locations, $p^{*}=p /(1-\tau)$. For firms in region $\mathrm{A}$, the prices at regional $\mathrm{A}$ markets and regional $\mathrm{B}$ markets are:

$p=\sigma \cdot \frac{1}{k_{B}} a_{m} \cdot W_{A} /(\sigma-1)$

$p^{*}=\sigma \cdot \frac{1}{k_{B}} a_{m} \cdot w_{A} /[(\sigma-1)(1-\tau)]$

Similarly, for firms in region B, the prices at regional A markets and regional $\mathrm{B}$ markets are:

$\bar{p}=\sigma \cdot \frac{1}{k_{A}} a_{m} \cdot W_{B} /[(\sigma-1)(1-\tau)]$

$\bar{p}^{*}=\sigma \cdot \frac{1}{k_{A}} a_{m} \cdot w_{B} /(\sigma-1)$

Among the above, $W_{A}$ denotes the nominal return of factors of the private sector in region $\mathrm{A}$ and $W_{B}$ denotes the nominal return of the private sector in region $\mathrm{B}$.

\subsection{Scale of Firms}

Firms use price markup to maximize the firm's profits. In equilibrium, margin is zero. So, the output of representative firm in region $\mathrm{A}$ is $X_{i}=\frac{(\sigma-1) F k_{B}}{a_{m}}$.

Similarly, the output of representative firm in region B is: $x_{i}=(\sigma-1) F k_{A} / a_{m}$.

\subsection{The Number of Private Sector Companies}

According to the deformation of $x=(\sigma-1) F k / a_{m}$, the number of production factors of private sector firms is $F+\frac{1}{k} a_{m} X=\sigma F . f_{M}$ denotes the total amount of the factors in an economic system. Then, the number of species is $N=f_{M} /(\sigma F)[12-15]$. are:

In equilibrium, the number of firms in regions $\mathrm{A}$ and $\mathrm{B}$

$n=f_{A} /(\sigma F)$ and $n^{*}=f_{B} /(\sigma F)$

Among above, $f_{M}=f_{A}+f_{B}, \quad f_{A}$ and $f_{B}$ denote quantities of production factors in regions $\mathrm{A}$ and $\mathrm{B}$, respectively. Assume that one firm manufactures one product, so that the number of firms is equal to the number of products. Then, for a region, the number of Product Category is proportional to the number of production factors, and the flow of productive factors is equivalent to the transfer of firms.

\subsection{Corporate Earnings}

In region $\mathrm{A}$, let $\mathrm{x}$ is the output of regional representative firm, and let $\mathrm{P}$ is the ex-factory price of good. Then, the total revenue is $R_{A}=p x$. Assuming the market clearing, in this case,

$p X=p c_{A}+p^{*} c_{A}^{*}$

where $c_{A}$ denotes the volume of sales in the local market and $C_{A}{ }^{*}$ denotes the number of goods of region A for sale to region $\mathrm{B}$ markets. Because of the existence of the transportation cost, the actual number of products offered by regions $\mathrm{A}$ to $\mathrm{B}$ is $c_{A}^{*} /(1-\tau)$. Then, the total output of firms is equal to the sales in two areas. It is

$X=c_{A}+c_{A}^{*} /(1-\tau)$

Meeting utility maximization, the consumption function of private products is:

$c_{i}=\left(p_{i} / P_{M}\right)^{\frac{1}{\rho-1}} C_{M}=\left(p_{i} / P_{M}\right)^{-\sigma} C_{M}$

Indices of Private product price is $P_{M}=\left[\sum_{i=1}^{N} p_{i}^{(1-\sigma)}\right]^{\frac{1}{1-\sigma}}$. The demand function is $\quad c_{i}=\mu Y \cdot \frac{p_{i}{ }^{-\sigma}}{P_{M}{ }^{1-\sigma}} \quad$ and $C_{A}=(1-\mu) \cdot \frac{Y}{p_{A}}$. Using the assumption that the income equals to the expenditure, we can draw:

$c_{A}=\mu_{A} \cdot E_{A} \cdot p^{-\sigma} / \Delta_{A_{N}}$

$c_{A}^{*}=\mu_{B} E_{B}[p /(1-\tau)]^{-\sigma} / \Delta_{B_{N}}$

$R_{A}=p X$

$=\mu_{A} \cdot E_{A} \cdot p^{-\sigma+1} / \Delta_{A_{N}}+\mu_{B} E_{B}[p /(1-\tau)]^{-\sigma+1} / \Delta_{B_{N}}$

Among the above, 


$$
\Delta_{A_{N}}=\int_{0}^{N} p^{1-\sigma} d i \quad \Delta_{B_{N}}=\int_{0}^{N} p^{1-\sigma} d i[1,2]
$$

$\mu>0, \quad \rho<1, \sigma>1 ; C_{M}$ denotes the demand for private products; $C_{A}$ denotes the demand for public products; $\mu$ denotes the ratio of spending on private products. Let $Y_{A}$ is the total income of region A. Let $Y_{B}$ is the total income of region $\mathrm{B}$. The total regional incomes can be expressed as:

$Y_{i}=w_{i} f_{i}$

In equilibrium, the expenditure is equal to the income. By equation (1), (8) and (9), the function (7) can be rewritten as:

$$
R_{A}=\frac{\mu_{A} W_{A} f_{A}}{n+\phi n^{*}\left(\frac{k_{A}}{k_{B} W}\right)^{1-\sigma}}+\frac{\mu_{B} W_{B} f_{B} \phi}{\phi n+n^{*}\left(\frac{k_{B}}{k_{A} W}\right)^{1-\sigma}}
$$

where denotes trade freedom; $\phi=(1-\tau)^{\sigma-1} \in[0,1]$; $W=\frac{W_{A}}{W_{B}}$. When $\tau$ is close to one, is equal to zero.

\section{EFFECT OF SPATIAL SPILLOVER EFFECTS OF PUBLIC SERVICES ON THE RETURN RATES OF FACTORS}

Consumer demands for products of the two regions. Let $C_{A A}$ denotes the quantity demanded of Region A for local goods. Let $C_{A B}$ denotes the quantity demanded of region A for Region B. According to the previous formula, there is

$\frac{C_{A A}}{C_{A B}}=\left(\frac{p_{A}}{p_{B} /(1-\tau)}\right)^{-\sigma}$

Similarly,

$\frac{C_{B A}}{C_{B B}}=\left(\frac{p_{A} /(1-\tau)}{p_{B}}\right)^{-\sigma}$

For the consumer in region $\mathrm{A}$, let $Z_{A A}$ is the proportion of spending on private goods of area $\mathrm{A}$ to spending on private goods of area $\mathrm{B}$. Then, $Z_{A A} /\left(1+Z_{A A}\right)$ is spent in region $\mathrm{A}$ with the total expenditure of private goods. Similarly, $Z_{A B} /\left(1+Z_{A B}\right)$ is expenditure spent in region $\mathrm{A}$ by the region $\mathrm{B}$ consumer within total expenditure of private goods.

$Z_{A A}=\left(\frac{f_{A}}{f_{B}}\right)\left(\frac{k_{A} W_{A}(1-\tau)}{k_{B} W_{B}}\right)^{-\sigma+1}$
$Z_{A B}=\left(\frac{f_{A}}{f_{B}}\right)\left(\frac{k_{A} W_{A}}{k_{B} W_{B}(1-\tau)}\right)^{-\sigma+1}$

The total income of a resident is the total expenditure on two regional products of two regions. The total revenue for area $\mathrm{A}$ is $Y_{i}=w_{i} f_{i}$. The total expenditure is divided into spending on public products and spending private products. The ratio of spending on private products is $\mu_{i}$. By that equals total revenue is equal to aggregate expenditure, we reach:

${ }_{W_{A}} f_{A}=\mu_{A} \frac{Z_{A A}}{1+Z_{A A}} Y_{A}+\mu_{B} \frac{Z_{A B}}{1+Z_{A B}} Y_{B}+G_{A}$

$w_{B} f_{B}=\mu_{A} \frac{1}{1+Z_{A A}} Y_{A}+\mu_{B} \frac{1}{1+Z_{A B}} Y_{B}+G_{B}$

By equation 14, we have :

$\mu_{A}=\mu_{A} \frac{Z_{A A}}{1+Z_{A A}}+\mu_{B} \frac{Z_{A B}}{1+Z_{A B}} \frac{W_{B} f_{B}}{W_{A} f_{A}}$

\subsection{A One-Way Overflow}

Public service spillover has the characteristics of multiple space and multi field. In the framework of two regions, we might as well discuss the case of only one regional public services spill. Assuming that the public service of region B spills over into region A, that enjoys this overflow. The impact is correlative positively with the amount of overflow. In order to simplify the analysis, define $k_{A}=1, \mu_{A}=\mu_{B}$. The total derivative of formula (17) is:

$$
\begin{aligned}
& d\left(\mu_{A}\right)=\left(\mu_{A} \frac{1}{\left(1+Z_{A A}\right)^{2}} \frac{\partial Z_{A A}}{\partial W_{A}}+\mu_{B} \frac{1}{\left(1+Z_{A B}\right)^{2}} \frac{\partial Z_{A B}}{\partial W_{A}} \frac{W_{B} f_{B}}{W_{A} f_{A}}\right. \\
& \left.-\mu_{B} \frac{Z_{A B}}{1+Z_{A B}} \frac{W_{B} f_{B}}{W_{A}{ }^{2} f_{A}}\right) d W_{A}+\left(\mu_{A} \frac{1}{\left(1+Z_{A A}\right)^{2}} \frac{\partial Z_{A A}}{\partial k_{B}}\right. \\
& \left.+\mu_{B} \frac{1}{\left(1+Z_{A B}\right)^{2}} \frac{\partial Z_{A B}}{\partial k_{B}} \frac{W_{B} f_{B}}{W_{A} f_{A}}\right) d k_{B}
\end{aligned}
$$

Above equation can be rewritten as:

$$
\begin{aligned}
& \frac{(1-\sigma)(1-\tau)^{-\sigma+1}}{\left(1+\left(\frac{f_{A}}{f_{B}}\right)\left(\frac{1}{k_{B}} W(1-\tau)\right)^{-\sigma+1}\right)^{2}}+ \\
& \frac{d\left(\ln W_{A}\right)}{d\left(\ln k_{B}\right)}=\frac{\frac{(1-\sigma)(1-\tau)^{\sigma-1}}{\left(1+\left(\frac{f_{A}}{f_{B}}\right)\left(\frac{1}{k_{B}} W\right)^{-\sigma+1}(1-\tau)^{\sigma-1}\right)^{2}}}{\frac{-(\sigma-1)(1-\tau)^{-\sigma+1}}{\left(1+\left(\frac{f_{A}}{f_{B}}\right)\left(\frac{1}{k_{B}} W(1-\tau)\right)^{-\sigma+1}\right)^{2}}-} \\
& (1-\tau)^{\sigma-1}\left(\sigma+\left(\frac{1}{k_{B}} w\right)^{-\sigma+1}(1-\tau)^{\sigma-1}\right) \\
& \left(1+\left(\frac{f_{A}}{f_{B}}\right)\left(\frac{1}{k_{B}} W\right)^{-\sigma+1}(1-\tau)^{\sigma-1}\right)^{2}
\end{aligned}
$$

In short-term balanced, two regional factors are not flow, so $f_{A}=f_{B}$. This formula is more complex and it is hard to 


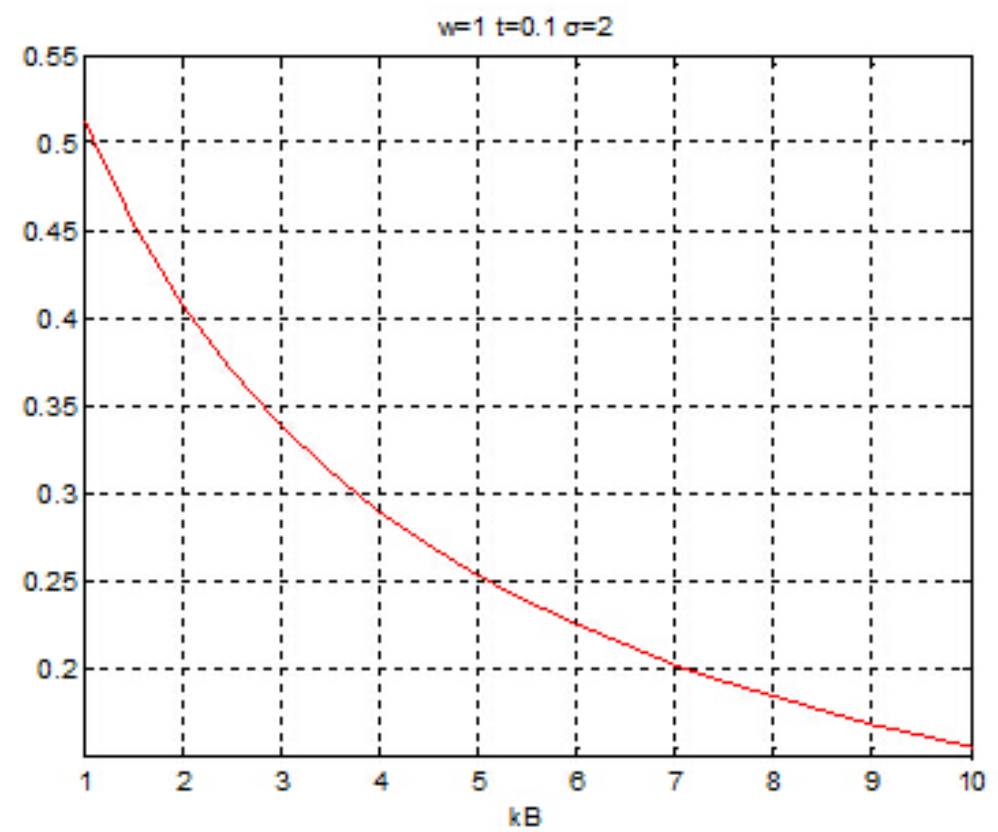

Fig. (1). Spillover effects of public services in region B.

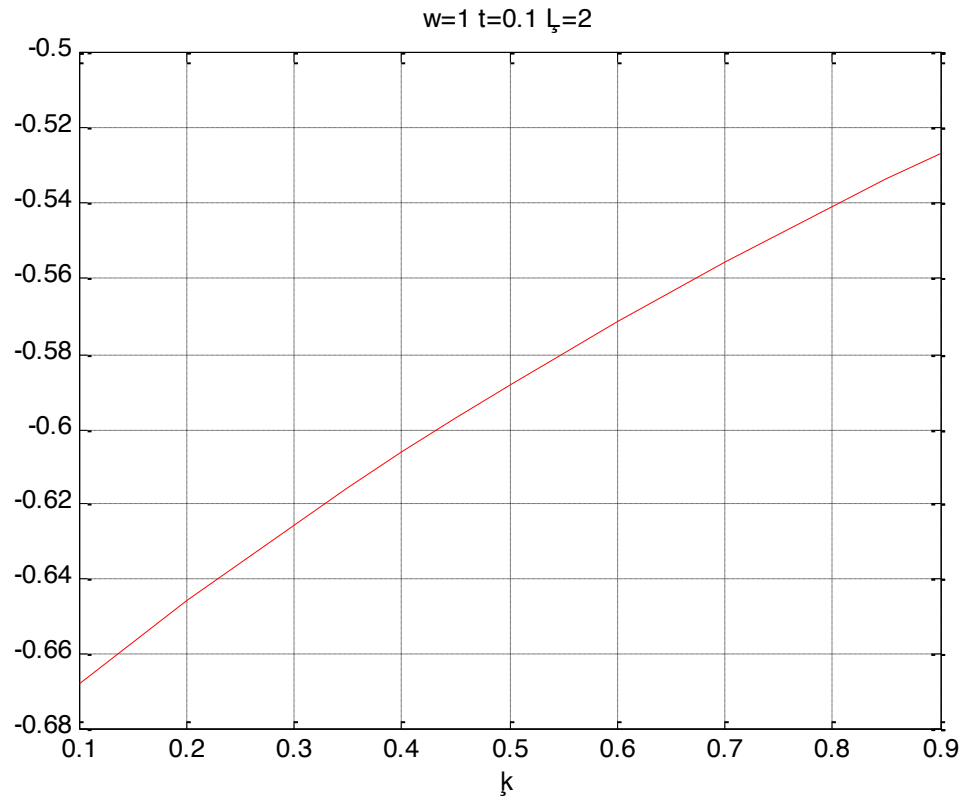

Fig. (2). Growth rate of costs and overflow.

see spill-over effects of the public services. Next, this paper is to analyze the impact by using numerical simulation given in Fig. (1).

As the chart in picture 1 shows, $d \ln w_{A} / d \ln k_{B}>0$ when $k_{B} \in(1,10)$. As $k_{B}$ increases, $W_{A}$ rises monotonically. This means that the more the overflow of public services in region $\mathrm{B}$, the higher the factor yields in region $\mathrm{A}$. Because the function curve is concave upward, its slope is getting smaller. Therefore, the impact on factor income when public service overflow is less, is bigger than the impact when public service overflow more. The spillover effect showed significant influence on factor income. With the increase of public service overflow from another area, it reduces the cost of production, and draws factors into local markets, thereby benefitting the spatial aggregation.

In another sense, if the region A did not make full use of public services to obtain social benefits or spatial spillover did not sufficiently supply the public services, those will indirectly lead to the increase of production cost. $k_{B}^{-1}$ is regarded as cost growth $\alpha(\alpha>1)$. Put $\alpha$ into formula (17), we can draw the Fig. (2) by using the same way as above. It shows $d \ln W_{A} / d \ln \alpha<0$. As $\alpha$ rises, $d \ln w_{A} / d \ln \alpha$ 
becomes smaller. This shows that the spillover of public services will reduce the effective yield of public services. And then it will effect on Factor income, and is not conducive to factor inflows. The situation will improve with the public services increase. This reflects the negative effect of the local public service overflow on local markets.

\subsection{Two-Way Overflow}

Spillover effect of public services on return rates of factors is called the spatial spillover effect. The following article will discuss the spatial spillover effect under the case of public service two-way overflow. In short-term, because the expenditure of public services to total expenditure is constant, we can get

$$
\begin{aligned}
& \frac{d W_{A}}{d k_{B}}= \\
& -\frac{\mu_{A} \frac{1}{\left(1+Z_{A A}\right)^{2}} \frac{\partial Z_{A A}}{\partial k_{B}}+\mu_{B} \frac{1}{\left(1+Z_{A B}\right)^{2}} \frac{\partial Z_{A B}}{\partial k_{B}} \frac{W_{B} f_{B}}{W_{A} f_{A}}}{\mu_{A} \frac{1}{\left(1+Z_{A A}\right)^{2}} \frac{\partial Z_{A A}}{\partial W_{A}}+\mu_{B} \frac{1}{\left(1+Z_{A B}\right)^{2}} \frac{\partial Z_{A B}}{\partial W_{A}} \frac{W_{B} f_{B}}{W_{A} f_{A}}} \\
& -\quad \mu_{B} \frac{Z_{A B}}{1+Z_{A B}} \frac{W_{B} f_{B}}{W_{A}^{2} f_{A}}
\end{aligned}
$$

In equilibrium, $f_{A}$ is equal to $f_{B}, W_{A}$ is equal to $W_{B}$ and $k_{A}$ is equal to $k_{B}$. Defined $\mu_{A}=\mu_{B}=\mu$. We have $Z_{A A}=(1-\tau)^{-\sigma+1}, Z_{A B}=(1-\tau)^{\sigma-1}$. Equation 19 is simplified as

$$
\frac{d W_{A}}{d k_{B}}=\frac{2 W_{A}(1-\sigma)(1-\tau)^{-\sigma+1}}{k_{B}\left[(1-2 \sigma)(1-\tau)^{-\sigma+1}-1\right]}
$$

As a result of $\sigma>1, \quad k_{B} \geq 1 \quad$ and $\tau<1$,
$\frac{2 W_{A}(1-\sigma)(1-\tau)^{-\sigma+1}}{k_{B}\left[(1-2 \sigma)(1-\tau)^{-\sigma+1}-1\right]}>0$. It indicates that yield rate $W_{A}$ rises with spill rate $k_{B}$ increasing. Hence, when the spatial spillover of public services is two-way, the amount of overflow will make the elements of different yield difference and facilitate the flow of factors of production.

\subsection{The Influence of the Change of $\sigma$}

The change of elasticity of substitution, transaction cost and factor yield will influence the spatial spillover effect. The article will be having extended discussions on the influence.

In short-term balanced, $f_{A}$ is equal to $f_{B}$. Put $\frac{f_{A}}{f_{B}}=1$ in equation 18 ,

$$
\begin{gathered}
\frac{W(1-\sigma)(1-\tau)^{-\sigma+1}}{\left(1+(k W(1-\tau))^{-\sigma+1}\right)^{2}}+ \\
\frac{d\left(\ln W_{A}\right)}{d\left(\ln k_{B}\right)}=\frac{\frac{(1-\sigma)(1-\tau)^{\sigma-1}}{\left(1+(k W)^{-\sigma+1}(1-\tau)^{\sigma-1}\right)^{2}}}{\frac{W(1-\sigma)(1-\tau)^{-\sigma+1}}{\left(1+(k W(1-\tau))^{-\sigma+1}\right)^{2}}+} \\
\frac{(1-\tau)^{\sigma-1}\left(-\sigma-(k W)^{-\sigma+1}(1-\tau)^{\sigma-1}\right)}{\left(1+(k W)^{-\sigma+1}(1-\tau)^{\sigma-1}\right)^{2}}
\end{gathered}
$$

where $k=\frac{k_{A}}{k_{B}}, w=\frac{W_{A}}{W_{B}}$. Next, in this paper, numerical simulation is carried out by using the software of MATLAB to discuss the possible change of the spatial spillover effect in different conditions.

Take $w=1.5,2,3$, when $\tau=0.1, k=0.5,2$. We can get Figs. (3 and 4 ) by simulation.

As image 3, 4 indicate, no matter whether $k=0.5$ or $k=2$, $d\left(\ln w_{A}\right) / d\left(\ln k_{B}\right)$ is greater than zero. It shows that the effect that public service of region B spillovers on factor returns of region $\mathrm{A}$ is positive with the elasticity of substitution. When the range of $\sigma$ is from 1 to 3 , the curve is steep; when $\sigma>3$, it will be flat. These show that the spatial spillover effect will be even more pronounced, when $\sigma$ is small. The three curves correspond to $w=1.5,2$ and 3, respectively, from top to down. The distance between curves in Fig. (4) is more than the one in Fig. (3), that reflects the spatial spillover effect is weaken with $\mathrm{k}$.

Take $w=1.5,2,3, \tau=0.1, k=0.5,2$. We can get Figs. (5 and 6) through the numerical simulation.

As you can see from Figs. (5 and $\mathbf{6}$ ), whether $k$ is greater or less than 1, the elasticity of substitution and spatial spillover effect are directly related. In the picture, there are certain points such as at left of the point, curve is steep trend and at the right, curve becomes flat or even decline, showing a different trend. The greater the value of $\mathrm{k}$, the later this point appears, which suggests that the influence of the elasticity of substitution on the spatial spillover effects is greater with $k$.

There are two points for comparing these figures. First, elasticity of private product substitution affect the effect of public service space spillover on factor income rate, but does not alter the positive and negative. Second, the overflow ratio between different regions influences $\sigma$ 't impact. When a regional spatial spillover is less than other areas, the spillover effect increase with $\sigma$. Otherwise, initially, the space spillover effect of public services is obvious with $\sigma$. When $\sigma$ increases to some extent, its influence will gradually tend to zero. In this case, the spatial spillover effect can be neglected as it does not affect the factor income. 


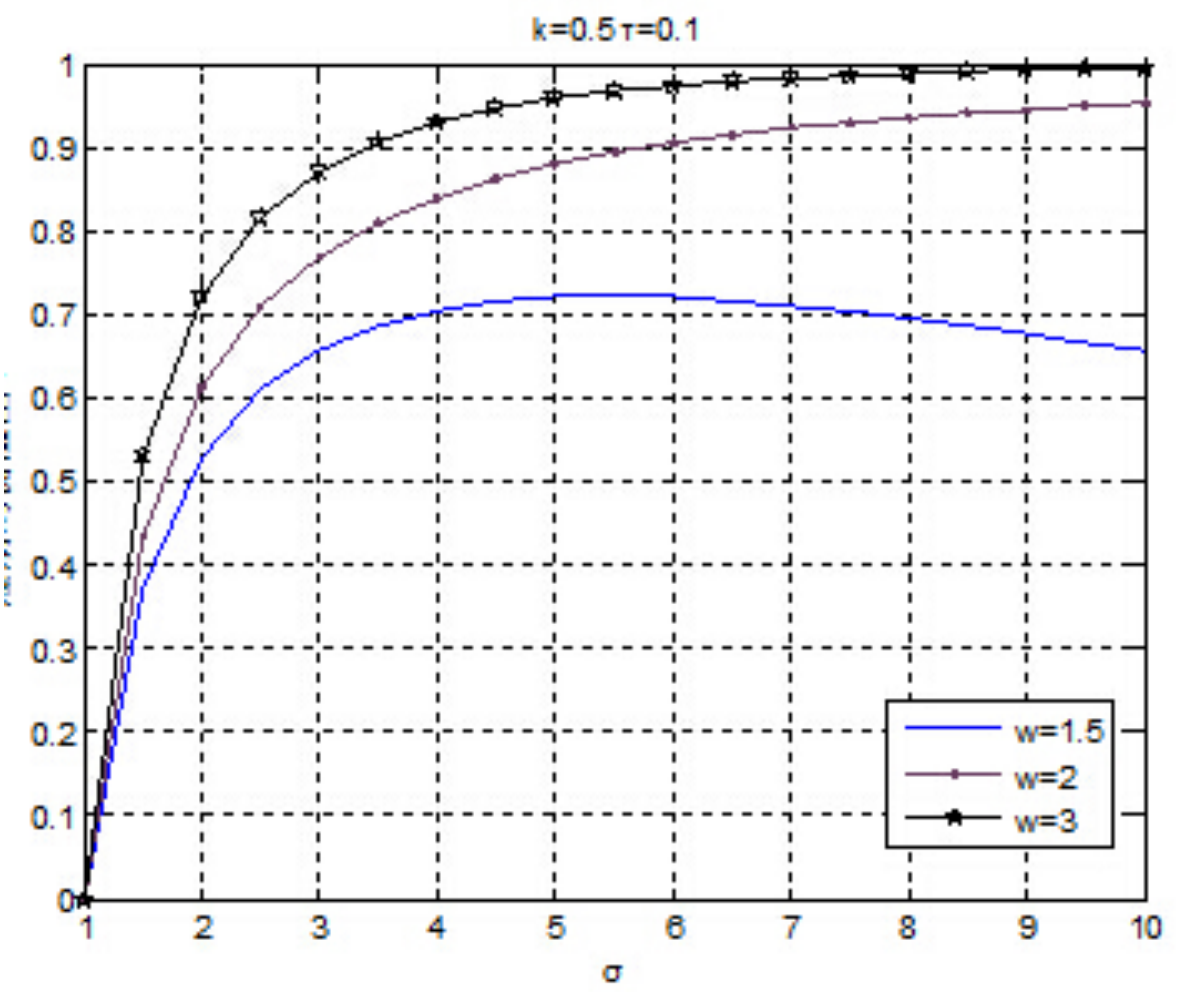

Fig. (3). The influence of $\sigma$ on spatial spillover effect, $\mathrm{k}=0.5, \mathrm{w}>1$.

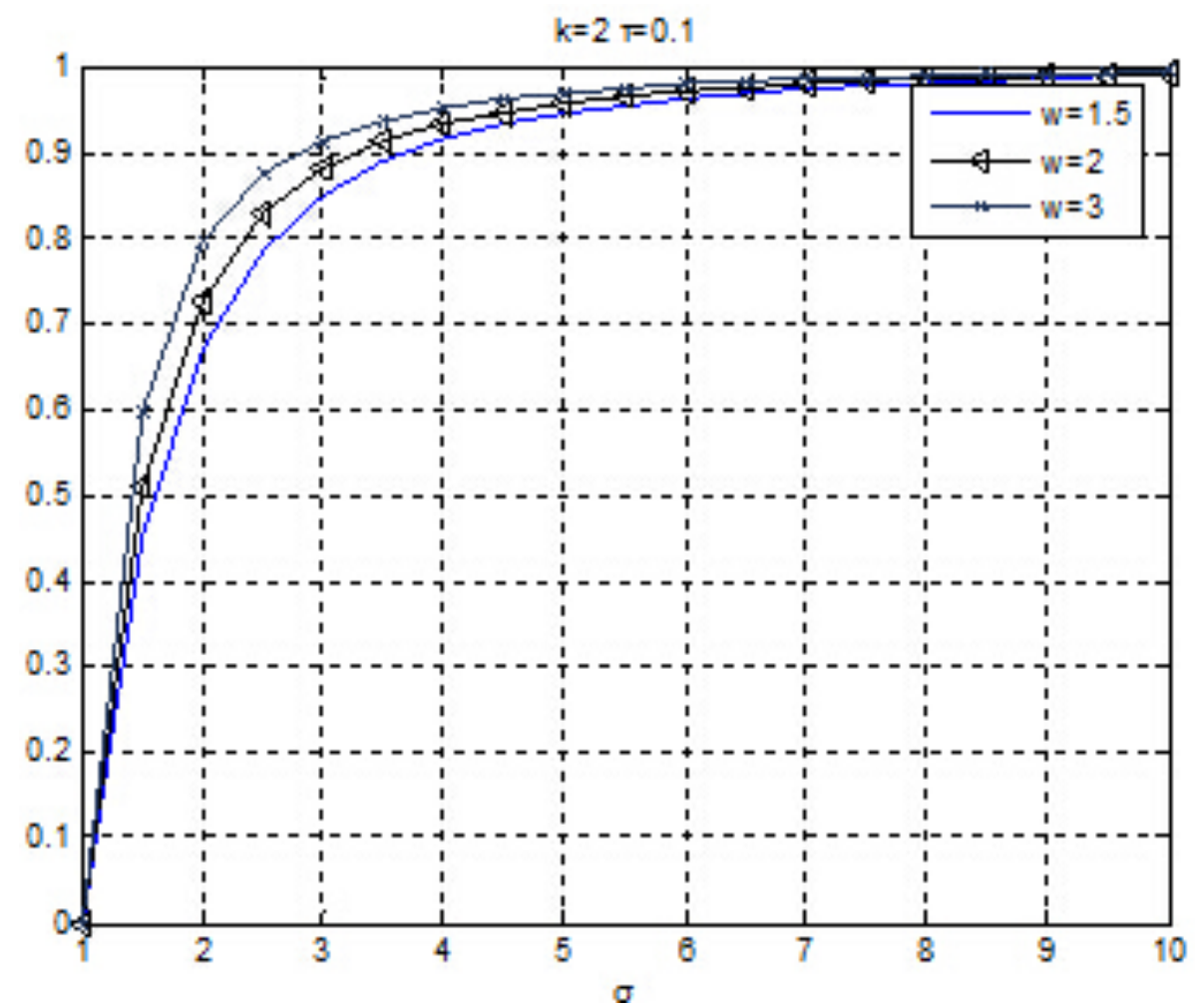

Fig. (4). The influence of $\sigma$ on spatial spillover effect, $k=2, w>1$. 


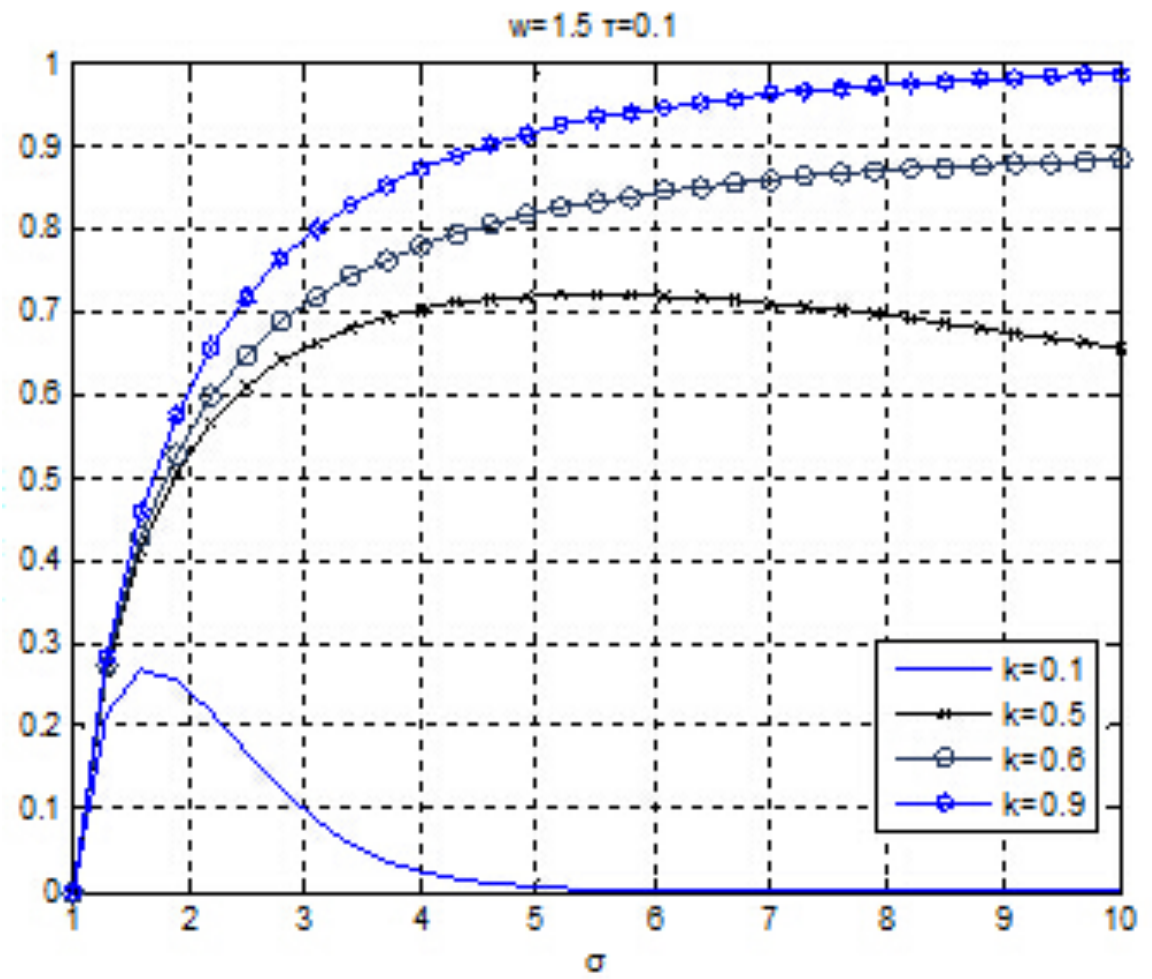

Fig. (5). The influence of $\sigma$ on spatial spillover effect, $w=1.5, \mathrm{k}<1$.

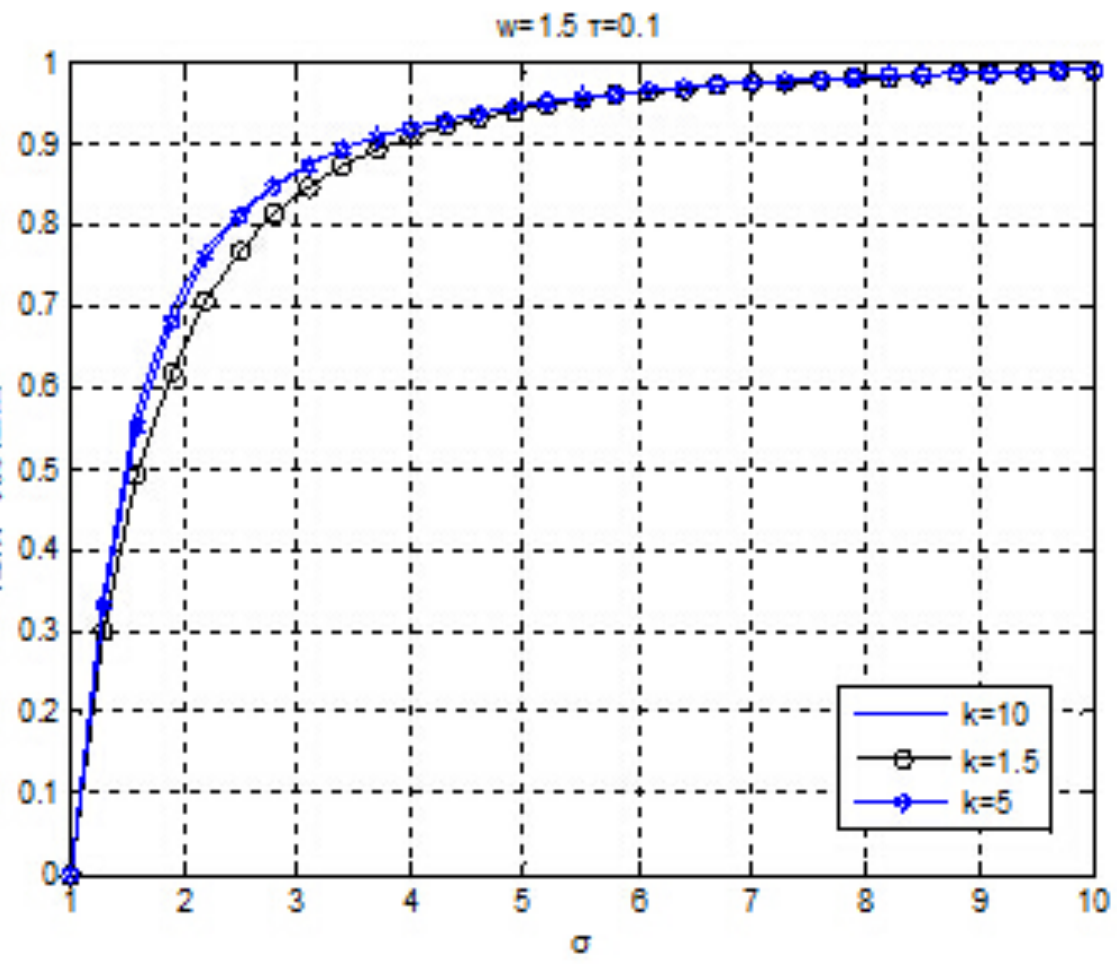

Fig. (6). The influence of $\sigma$ on spatial spillover effect, $w=1.5, \mathrm{k}>1$. 


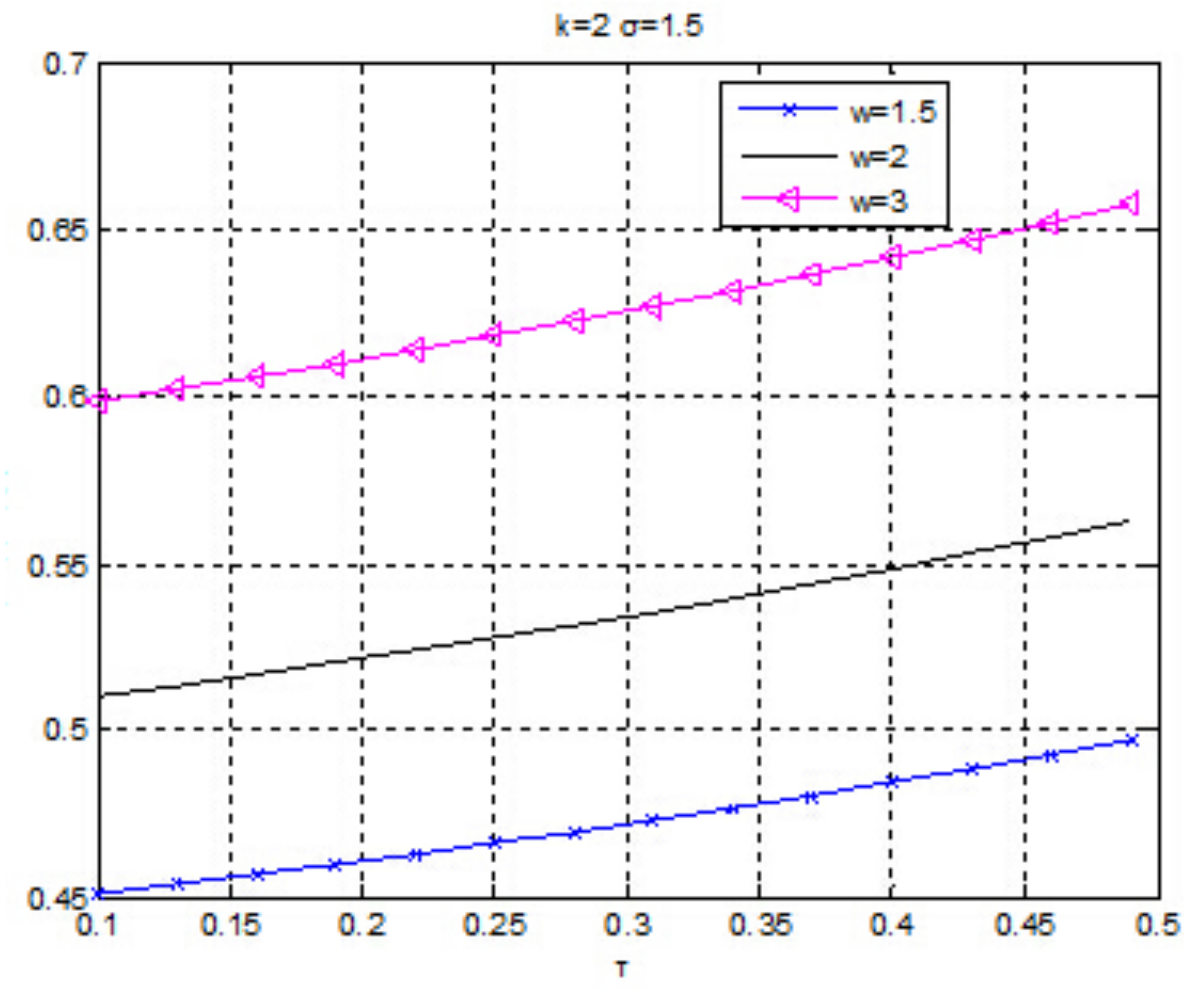

Fig. (7). The influence of $\tau$ on spatial spillover effect.

\subsection{The Influence of the Change of $\tau$}

From the diagram 7 it is obvious, no matter what the value of transaction cost is, $d\left(\ln w_{A}\right) / d\left(\ln k_{B}\right)$ is greater than zero and increases along with the increase of transaction cost. Although the change of $\mathrm{w}$ and $\mathrm{k}$ will cause the curve move up and down, yet it does not change the shape of the curve. Those suggest that the increase of interregional transportation cost reduces the liberalization of trade. Due to the increase in transaction costs, the firm is more dependent on the public services. The spatial spillover effect is more obvious. At the same time, the yield differentials between the two regions and the increase of two regional public service overflow gap will have further significant effects, Fig. (7).

\section{CONCLUSION}

To sum up, in the short-term equilibrium, a regional public service overflow will impact on the adjacent area. The more the spillover adjacent area gets, the more the rate of factor income will be improved. Elasticity of substitution, factors yield, transaction cost and space overflow ratio will have positive impact on the spillover effect, whether big or small. Therefore, a local government should not only pay attention to the quantity and the quality of public services or products, but also on the effective utilization and the number of demands. Public services should be provided based on the actual needs. If the government blindly expands the scope or increases the number of public services, this will undoubtedly cause a huge waste of resources and might hamper local economic development.

\section{CONFLICT OF INTEREST}

The authors confirm that this article content has no conflict of interest.

\section{ACKNOWLEDGEMENTS}

Declared none.

\section{REFERENCES}

[1] L. Anselin, "Local indicators of spatial association-LISA," Geographical Analysis, vol. 27, no. 2, pp. 93-115, 1995.

[2] H. Liu, Z. Wang, and T. Liu, "The impact of the supply of local public services on the flow of inter-regional factors-an equilibrium analysis without considering the local transaction costs," Systerms Engineering, vol. 9, pp. 73-79, 2007.

[3] W. Pan, "Regional linkage and the spatial spillover effects on regional economic growth in china," Economic Research Journal, vol. 4, pp. 54-65, 2012. (in Chinese)

[4] B. H. Baltagia, E. Peter, and M. Pfaffermayr, "A generalized spatial panel data model with random effects," Econometric Reviews, vol. 32, no. 5-6, 2013.

[5] H. An, The Principle of Spatial Economics the Economic, Science Press: Beijing, 2005, pp. 10-80.

[6] M. D. Partridge, M. Boarnet, S. Brakman, and G. Ottaviano, "Introduction: whither spatial econometrics?" Journal of Regional Science, vol. 52, no. 2, pp. 167-171, 2012

[7] S. Gibbons, and H. G. Overman, "Mostly pointless spatial econometrics," Journal of Regional Science, vol. 52, no. 2, pp. 172-191, 2012.

[8] J. P. Elhorst, "Spatial Panel Models Handbook of Regional Science 2014," Springer: Berlin Heidelberg, 2013, pp. 1637-1652.

[9] X. Song, W. Deng, and Y. Liu, "Spatial spillover and the factors influencing public service supply in Sichuan province," Journal of Mountain Science, vol. 11, no. 5, pp. 1356-1371, 2014.

[10] J. P. LeSage, "Discussion: applications and innovations in spatial econometrics," Journal of Agricultural and Applied Economics, vol. 43, no. 3, pp. 339, 2011. 
[11] J.P. Elhorst, “Applied spatial econometrics: raising the bar" Spatial Economic Analysis, vol. 5, no. 1, pp. 9-28, 2010.

[12] J. P. Elhorst, "Specification and estimation of spatial panel data models," International Regional Science Review, vol. 26, no. 3, pp. 244-268, 2003.

[13] T. Ma, T. Hong, and H. Zhang, "Tourism spatial spillover effects and urban economic growth," Journal of Business Research, vol. 68 , pp. 74-80, 2014
[14] T. Tong, T.H. E. Yub, S.H. Chob, K. Jensenb, and D. De La T. Ugarte, "Evaluating the spatial spillover effects of transportation infrastructure on agricultural output across the United States," Journal of Transport Geography, vol. 30, pp. 47-55, 2013.

[15] J. Mennis, P. W. Harris, Z. Obradovic, A.J. Izenman, H.E. Grunwald, and B. Lockwood, "The effect of neighborhood characteristics and spatial spillover on urban juvenile delinquency and recidivism," The Professional Geographer, vol. 63, no. 2, pp. 174-192, 2011

Received: September 16, 2014

Revised: December 23, 2014

Accepted: December 31, 2014

(C) Li and Zhang; Licensee Bentham Open.

This is an open access article licensed under the terms of the (https://creativecommons.org/licenses/by/4.0/legalcode), which permits unrestricted, non-commercial use, distribution and reproduction in any medium, provided the work is properly cited. 